Boise State University ScholarWorks

Educational Technology Faculty Publications and

Presentations

Department of Educational Technology

$10-1-2015$

\title{
How Debriefing Strategies Can Improve Student Motivation and Self-Efficacy in Game-Based Learning
}

Cigdem Uz Bilgin

Yildiz Technical University

Youngkyun Baek

Boise State University

Hyungsung Park

ShinGu University 


\title{
How Debriefing Strategies Can Improve Student Motivation and Self-Efficacy in Game-Based Learning
}

\author{
Cigdem Uz Bilgin \\ Yildiz Technical University \\ Youngkyun Baek \\ Boise State University \\ Hyungsung Park \\ ShinGu University
}

\begin{abstract}
Debriefing is an important step in game-based learning environments. In the present study, the effect of different debriefing strategies in terms of two factors, grouping (self vs. team) and timing (in-game vs. post-game), was investigated on the motivation and self-efficacy levels of students. In a 2x2 ANOVA design, 62 sixth grade students were randomly assigned into two debriefing groups: self-debriefing and team debriefing. About half of members in each group performed either one of the two debriefing: in-game debriefing or post-game debriefing. Students in the self-debriefing as well as in the team-briefing group played the game three days a week over nine weeks. As students finished the task, motivation and self-efficacy scales were administered and semi-structured interviews were conducted. Findings indicate that students showed higher motivation and self-efficacy scores in the team debriefing than in the selfdebriefing. Moreover, the in-game debriefing group outperformed the post-game debriefing group in terms of self-efficacy and motivation levels. Semi-structured interviews supported the quantitative results that students benefited more from collaborative debriefing sessions.
\end{abstract}

Keywords: game-based learning, debriefing, student motivation, self-efficacy, collaborative learning environments

\section{Introduction}

There has been significant development in game-based learning in the past decade. Many previous studies in this field have demonstrated that learning motivation and self-efficacy can be maintained through educational games. As a result, many educators have become interested in making use of games in education (Papastergiou, 2009; Vos, Van der Meijden \& Denessen, 2011). However, engagement in the game may not be the same among the individuals in terms of learning motivation and self-efficacy because they cannot equally reflect on the experiences, thus some of them may have drawn limited conclusions from their gaming experiences (Peters \& Vissers, 2004). Debriefing is an important and first step in using educational games in that it tries to maintain student's engagement and motivation.

Debriefing, a type of instructional scaffold, aims to encourage learners to reflect on the gaming experience (Van der Meij et al. 2013). Learners need to consciously analyze and review the events that occurred during the gaming process. Fanning and Gaba (2007, p.116) defined debriefing as "facilitated or guided reflection in the cycle of experiential learning.” The debriefing sessions were used to "confirm participants' knowledge, clarify misunderstandings, correct mistakes, apply experiences to other situations and reinforce previous learning" (Asakawa \& Gilbert, 2003, p.15). Debriefing originated with the military, where participants in a war game came together to talk about their experiences, to discuss the actions that occurred and to develop new strategies (Van der Meij et al., 2013). Most educational games omit debriefing activities, however without debriefing sessions, the effect of the educational game may be greatly diminished, as some learners will see the activity as a game and not properly connect it to other situations or aspects of life (Nicholson, 2012). 
Two important components were described behind debriefing: the events which affected the player in a way that requires further consideration and the process needed to help the player through that consideration (Nicholson, 2012). Debriefing aims to transfer concepts and activities in the games to the settings outside the classroom, and also clears up any misunderstandings or mistakes. The result of the debriefing process is to make learners discover meaningful connections between the activity and their own lives, thus improving the learning that occurs from an experiential activity (Quinsland \& Ginkel, 1984). Previous studies comparing debriefing versus non debriefing found significant improvement in performance scores of participants in the debriefing group compared to the non-debriefing group (Savoldelli et al., 2006: Shinnick et al., 2011).

Several different approaches to debriefing have been proposed in the literature (Van Heukelom et al., 2010) and different models have been noted and different strategies described (Dufrene \& Young, 2013). While several researchers focused on the grouping factor during the debriefing sessions (self-debriefing vs. team debriefing) (Boet et al., 2011; Van der Meij et al., 2013), some of them focused on the different technologies used in debriefing sessions (video assisted vs. computer assisted) (Chronister \& Brown, 2012; Welke et al., 2009). Others emphasized the timing factor, or the time when debriefing sessions were performed (during the game vs. at the end of the game) (Van Heukelom et al., 2010). In addition, many previous studies compared debriefing versus no debriefing in terms of game scores and examined student perceptions about the value of the debriefing process (Cantrell, 2008; Morgan et al., 2009; Van Heukelom et al., 2010).

Previous studies comparing different debriefing strategies are rare and their results are inconsistent, generally focusing on one type of factor such as different types of technology, grouping or timing. Furthermore, in previous studies, the general aim was to explore the effect of different debriefing strategies on game performances, user beliefs about their learning achievements with surveys and questionnaires (Boet et al., 2011; Bond et al., 2006; Chronister \& Brown, 2012; Grant et al., 2010; Morgan et al., 2009). However, giving support for building higher game motivation and selfefficacy in game play beliefs are also essential objectives of debriefing. Because debriefing aims to resolve misunderstandings or mistakes that occurred during the gaming process, learners become more confident in their abilities to reach the specific goal. Confidence can be maintained by increasing their beliefs in their capabilities to produce given attainments (Bandura, 2000). Learners who have a low sense of self-efficacy for accomplishing a task may avoid it, which means that they are not motivated to act in ways they believe will result in negative outcomes (Schunk, 1991). The best motivating strategies can be listed as encouraging students to overcome challenges and to become competent. Debriefing sessions in serious games play an important role to clarify learners' misunderstandings and reduce negative feelings about aspects of the activities (Thiagarajan, 2004).

The present study compares the effects of different debriefing strategies in terms of grouping and timing factors on the students' motivation and self-efficacy levels. In order to achieve the objectives of this study, quantitative research methods (surveys or questionnaires) as well as qualitative research methods (interviews) are utilized for deeper understanding of the effects of different debriefing strategies.

\section{Literature Review}

\subsection{Models of Debriefing}

There are a number of models of debriefing that have been described and used in the literature which are based on Bloom's Taxonomy, Kolb (1984)'s experiential learning cycle and so forth (Nicholson, 2012; Sims, 2002). The present study used the EIAG (experience, identify, analyze and generalize) model of experiential learning (Bredemier et al., 1981) as the basis for the conceptual model. The main reason for choosing this model is its easy adaptation to other organizational settings. The EIAG debriefing model facilitates adaptation to different settings, especially academic games and provides a basic debriefing structure that facilitates generalization and validation of conclusions (Bredemier et al., 1981). This model includes four stages: experience, identify, analyze and generalize (Hawkins et al., 1999). The experience stage in this model is the gaming process which will be debriefed by the learners. From the gaming experience, learners talk about their goals, how comfortable or uncomfortable they feel in a particular role, what they worry about, what frustrates them, when they are happy, how they handle their discomfort, worries, frustrations, joy, and so forth (Bredemier, et al.,1981). The next three stages of debriefing focus on moving participants toward using these experiences. In the second stage, learners are asked to specify exactly what happened in descriptive terms. "What did you see or hear in the game?" "What happened?" "What were the activities of the high scorers?” In the 'analyze' section, learners begin to analyze which variable made the experience positive or negative and why. 
This is an author-produced, peer-reviewed version of this article. The final, definitive version of this document can be found online at Journal of Educational Computing Research, published by Sage. Copyright restrictions may apply. doi: 10.1177/0735633115598496

"How were you affected by this happening?” "What relationships do you see between...?” In the final stage, learners are asked to draw conclusions from the game about their world based on identification of the facts and analysis of cause and effect relationships (Bredemier, 1981).

Debriefing models are generally used with a facilitator who leads the learners through the process. Debriefing sessions can be accomplished using written assignments, class discussions, class presentations, discussion of team or personal reactions and so forth. In the next section, different debriefing strategies are described and discussed with empirical results.

\subsection{Debriefing Strategies}

Debriefing can be accomplished through several methods based on various factors. Previous experimental studies mainly explore four factors including timing, grouping, technology and facilitation and their relationships or combined effects on various dependent variables (Bond et al., 2006; Van Heukelom et al., 2010; Van der Meij et al., 2013). Different strategies based on these popular factors were applied and resulted in inconsistent results. These strategies include class discussions, written assignments, team discussions, individual reflections or class presentations. In the next section, these popular factors will be explained and empirical findings will be presented. The reason for choosing these factors is that they have been explored predominantly in the previous debriefing studies.

Timing is one of the important factors that affect the results of the debriefing sessions. Debriefing generally occurs after the game experience (Bond et al., 2006; Cantrell, 2008; Fanning \& Gaba, 2007; Gordon \& Buckley, 2009). However, there are conflicting opinions about the timing factor: while several researchers recommend debriefing at the end of the game which is a post-game debriefing (Bond et al., 2006, Van Heukelom et al., 2010), others believe that debriefing sessions during the game which is an in-game debriefing enhance the learning experience (Fritzche et al., 2004, Van der Meij, 2013). Schöen (1983) recommended keeping the delay between the learners' experience and the debriefing to a minimum because a short delay can be useful when emotions have run too high during the playing process and learners can cool down (as cited in Van der Meij, 2013). Moreover, in an in-game debriefing, the learners' memory is still fresh, thus learners can recall the events and actions more easily than in post-game debriefing. However, Van Heukelom et al. (2010) found that a game experience followed by a debriefing session helped participants learn more effectively, to understand better the correct and incorrect actions, and that overall it was more effective compared with debriefing that conducted in the game. Flanagan et al. (2004) supports the idea that uninterrupted debriefing sessions are essential to the game experience, debriefing sessions are conducted after the game and students can easily focus and get better results. Studies comparing debriefing's effects in terms of the timing factor are rare. Thus, the timing factor needed to be clarified further with respect to its effects on debriefing outcomes in future studies.

Grouping is another factor that has been cited in previous studies (Van der Meij et al., 2013; Tannenbaum \& Cerasoli, 2013). Debriefing sessions can be conducted with teams or individually. When the playing activity has been undertaken as a team, the debriefing also tends to be conducted with the team as a whole (Van der Meij et al., 2013). If a simulation game aims to support learning by individual participants, self-debriefing may suffice (Peter \& Vissers, 2004). This idea is supported by the study of Van der Meij et al. (2013) in which participants played "Lemonade Tycoon Deluxe," a strategy game played individually, and participants who had engaged in individual debriefing had higher game scores than those who had debriefed collaboratively. On the other hand, $\operatorname{Li}(2010)$ supported the idea that with collaboration, learners have a greater opportunity to clarify their concepts and principles. They get deeper understanding through mutual discussion. Learners who collaborate in debriefing activities would use strategies more precisely during game play on the strength of the other team members' experiences, so their game performance and feeling of competence would increase more than those of learners in individual self-debriefing. According to Astin (1999)'s theory, students who engage in academic discussions with peers may benefit motivationally, academically and socially. In the same context, Peters and Vissers (2004) emphasized group debriefing sessions in educational games that require collective learning or learning collaboratively. On the other hand, Tannenbaum and Cerasoli (2013), emphasize the alignment of levels in debriefing. According to Tannenbaum and Cerasoli (2013), there are three levels to be considered: participant level in which a debrief can be conducted either with a team or with an individual as the participants, focal level in which the focus should be considered (whether the debrief is focused primarily on improving the team as a whole or on independently improving each individual) and measurement level which involves considering whether the study measured performance at the individual level or at the team. The findings of Tannenbaum and Cerasoli (2013) support the idea that aligning participants, intentions, and measurement 
yield promising results. When the goal is to improve team effectiveness, debriefing sessions should be conducted collaboratively and focused on team performance; if the goal is to improve the individual performance, debriefings can be conducted individually.

There are numerous studies that explore the technology factor in debriefing sessions (Welke at al., 2009; Grant et al., 2010). With regards to the technology factor, debriefing can be conducted with computer-based multimedia, videoassisted, written assignments or class presentations. Opportunities to incorporate technologies for debriefing can be increased with new innovations in the digital world. Chronister and Brown (2012) used a comparative crossover design to compare the effects of debriefing with verbal feedback only with video-assisted debriefing and no significant difference was found in overall game performance scores between the groups. In another study, the effects of two different types of debriefing, oral debriefing and videotape-assisted debriefing, were compared and both debriefing methods were found to be effective (Grant et al., 2010). Welke et al. (2009) compared video-assisted oral debriefing and standardized computer-based multimedia debriefing and no significant differences were found between the groups in terms of game performance scores. Previous studies based on the technology factor show that the type of the technology is not an important indicator that affects the quality of the debriefing, even though as a factor, technology is a popular one. According to Clark (1983), media are mere vehicles that deliver instruction but do no influence student achievement. The active component in successful media treatments is not the media attribute because different media attributes produce similar results. Media has significant effects on the cost and speed of learning but only the use of appropriate instructional methods will influence the learning (Clark, 1994). In the present study, the major emphasis was on the method rather than the media in the debriefing activities.

Facilitation is another factor that has been studied in previous debriefing studies (Boet et al., 2011; Neill \&Wotton, 2011). Debriefing sessions can be conducted with a facilitator or not. Increasingly, due to the cost of expert debriefers, there has been interest in self-debriefing (Fanning \& Gaba, 2007). In fact, previous studies showed that learners were equally satisfied with both methods (self vs. facilitated) (Butler, 1993) and had similar game performance scores (Boet et al., 2011). In addition, a survey among 10,166 pilots who had flight simulator experience found no difference in appraised effectiveness for expert-led or self-debriefing (Neill \&Wotton, 2011). In sum, although facilitation has been explored in a wide range of studies, the findings from previous studies showed no significant difference between selfdebriefing and facilitated debriefing. In the present study, technology (media) and facilitation factors were not explored due to the conflicting and insignificant results of the previous studies and major emphasis was placed on the method rather than the media.

\section{Method}

\subsection{Purpose of the Study and Research Methods}

The purpose of the present study is to explore the effects of different debriefing strategies on learners' game motivation and self-efficacy in game playing. Mixed methods research was conducted which focuses on collecting, analyzing, and combining both quantitative and qualitative data in a single study. According to Creswell and Clark (2007), use of quantitative and qualitative approaches in combination provides a better understanding of research problems than either approach alone. Explanatory mixed methods design gives greater emphasis to the quantitative data and qualitative data can be used to gather an in-depth understanding of situations which cannot be observed by quantitative data.

In the present study, Moshi Monsters was chosen as an educational game which includes collaborative activities that were undertaken as a team. For the quantitative part of the study, grouping (self vs. team debriefing) and timing (ingame vs. post-game) factors were chosen as the modes for debriefing strategies due to the scarcity and inconsistency of previous studies. A two-way analysis of variance (ANOVA) was conducted to explore the effects of grouping and timing factors on learners' game motivation and self-efficacy levels. Motivation and self-efficacy were chosen as dependent variables, because one of the important goals of debriefing is to transform learners' perceptions of selfefficacy; the belief they hold in their capability to accomplish a task, which, in this respect refers to their ability to play the game (Agarwal et al., 2000). In essence, debriefing aims to change their beliefs that they are capable through game play to accomplish the desired goals and outcomes. 
Motivation and self-efficacy levels of students were measured with the Intrinsic Motivation Scale (McAuley et al., 1989) and the Video Game Self-efficacy Scale (Pavlas, 2010), respectively. Empirical results were supported with semi-structured interviews for providing thorough understanding of the different debriefing strategies.

\subsection{Participants}

The participants were 62 fourth grade students (32 male and 30 female) from an elementary school located in $\mathrm{K}$ province, South Korea. Their age ranged from 11 to 12 years old. These participants were from two classes enrolled in a semester of an Information, Communication and Technology course offered at their elementary school. They were selected as participants because this age group is malleable in debriefing (Pfefferbaum et al., 2015), as well as because Moshi Monsters is a game designed for students in grades 3 to 7.

A teacher taught two classes consisting of 27 hours of in-class instruction with a same curriculum of identical syllabi, exercises, homework and exams. All participants were present in all classes without any absence during the experiment. The course was designed to provide students with an opportunity to improve their computer skills and to enhance their computer knowledge as a result of game play. In this quasi-experimental study, a convenience sampling method with random assignment was used. Sixty two students were randomly assigned to the different debriefing groups. The distribution of the students to the different debriefing groups was: 15 students in the self and in-game debriefing group, 15 in the self and post-game debriefing group, 16 in the team and in-game debriefing group and 16 in the team and post-game debriefing group (Table 1 ).

Table1. Number of student in each group

\begin{tabular}{ccccc}
\hline & \multicolumn{4}{c}{ Group(male/female) } \\
& self-debriefing & team-debriefing & Total \\
\hline $\begin{array}{c}\text { Debriefing } \\
\text { Timing }\end{array}$ & in-game & $15(8 / 7)$ & $16(8 / 8)$ & $31(16 / 15)$ \\
& post-game & $15(8 / 7)$ & $16(8 / 8)$ & $31(16 / 15)$ \\
& Total & $30(16 / 14)$ & $32(16 / 16)$ & $62(32 / 30)$ \\
\hline
\end{tabular}

\subsection{Materials}

\subsubsection{Motivation Questionnaire}

The Intrinsic Motivation Scale (McAuley et al., 1989) was used to measure leaners' motivation to play the game. The scale measures participant reaction to a number of items along a 6-point Likert-type scale anchored from "strongly disagree" (1) to "strongly agree" (6), with subscales indicating interest, tension, effort, and competence. Internal consistency for the four subscales was generally quite adequate in terms of the alpha coefficient: interest $(\alpha=.78)$, tension ( $\alpha=.68)$, effort ( $\alpha=.84$ ), and competence $(\alpha=.80)$ (McAuley et al., 1989). The overall scale is also internally consistent with the alpha coefficient of .85 (McAuley et al., 1989). The questionnaire was developed for a basketball shooting game called "Horse" (McAuley et al., 1989) and was adopted for the game used in this study, "Moshi Monsters." The scale consists of items which indicate learners' perceptions about the game such as, "I think I am pretty good at this game." Other example questions from the scale are: "I put a lot of effort into this game," "I am satisfied with my performance in this game," "After playing the game for a little while, I felt pretty competent." This motivation questionnaire was composed of 18 items. Each question was weighted equally.

\subsubsection{Self-Efficacy Questionnaire}

The video game self-efficacy scale used in the present study was previously modified (Pavlas, 2010) from the Schwarzer and Jerusalem's scale of general self-efficacy (1995). The scale consists of ten items that reference an individual's belief in his or her ability to successfully complete tasks in a game. Participants respond to the measure along a 6-point Likert-type scale ranging from "strongly disagree" (1) to "strongly agree" (6). In samples from 23 
This is an author-produced, peer-reviewed version of this article. The final, definitive version of this document can be found online at Journal of Educational Computing Research, published by Sage. Copyright restrictions may apply. doi: 10.1177/0735633115598496

nations, Cronbach's alpha score ranged from .76 to .90 , with the majority in the high reliability range (Schwarzer \& Jerusalem, 1995). The self-efficacy scale is one-dimensional and consists of items such as "It is easy for me to stick to my plans and accomplish my goals in this game." Other example questions from the scale are: "If I am in trouble in the game, I can think of a solution," "I can usually handle whatever comes my way in a video game," and "I can remain calm when facing difficulties in the game because I can rely on my coping abilities.” This self-efficacy scale was composed of 10 questions. The Cronbach's $\alpha$ value of this test was .95.

\subsubsection{Semi-structured Interviews}

After the experimental process, semi-structured interviews were conducted with 16 students, four students from each of the four debriefing groups. Interview questions were gathered from Reed's (2012) Debriefing Experience Scale. The scale is developed from debriefing literature and expert opinion and includes questions about the debriefing experience. Interview questions in the present study try to reveal thoughts and feelings of learners about the debriefing process, their perceived learning and making connections and suggestions for the debriefing sessions. For this purpose, the following questions were asked of the students: "What are your feelings and thoughts about the debriefing process? Did your questions about the game get answered by debriefing? Was debriefing helpful in processing the game experience? Did debriefing help you to clarify problems? In your opinion, what can be done to make debriefing more efficient than now?”

\subsection{The Game}

Learners played Moshi Monsters as an educational game. Moshi Monsters is a free online educational game where users can adopt their own pet monster and go on various adventures with the character. Moshi Monsters, which was developed in the U.K., had 50 million registered users by the end of 2011 and expects to have 70 to 80 million members in 200 countries by the end of 2013 (Hall, 2011). Moshi Monsters is a free and safe game that children can play only with the permission of their parents. As part of the registration process, the site gathers a parent's email address and sends a confirmation e-mail that must be acknowledged in order to play the game. While playing the game, users can earn "Rox" by solving puzzles and completing many challenges to purchase gifts, food and other treats to care for their monsters.

The Puzzle Palace is a place in Moshi Monsters, where players can play puzzle quizzes to earn Rox, the currency of Monstro City. They can play the Daily Challenge or select a puzzle from the Hall of Puzzles (see Fig. 1). Players can also play separate types of quizzes, including general knowledge (Tricky Trivia) and Moshi Monster knowledge (Master of Moshi).

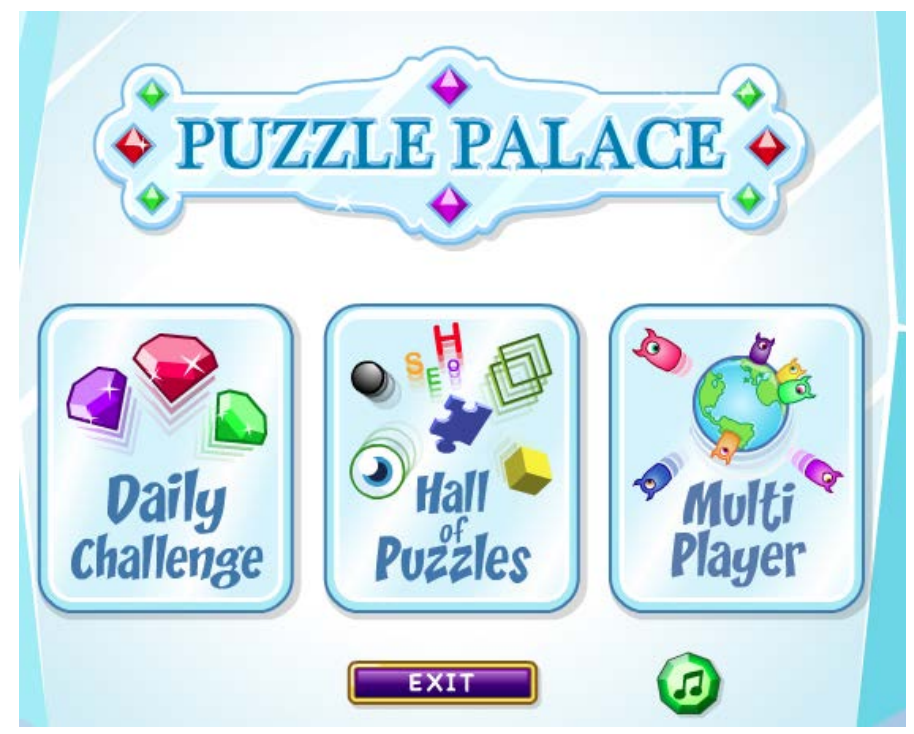

Figure 1. Moshi Monsters "Puzzle Palace” 
The Daily Challenge and Hall of Puzzles are two games in the Puzzle Palace. The players in Daily Challenge were allowed to play once a day. In The Daily Challenge, players answer a series of various questions from every category in the Hall of Puzzles. The difficulty level increases as the player progresses with correct answers (see Fig. 2).

\begin{tabular}{|c|c|c|c|}
\hline \multicolumn{4}{|c|}{ Get 5 Rox a day for each puzzle you play! } \\
\hline \&: Bubble Trouble & R-- & (3) Time Tangle & R-- \\
\hline Color Chaos & $R=-$ & Shape Shake & Q-- \\
\hline (2) Eyes Spy & $R=$ & 赕 line Dance & R-- \\
\hline 四斯 Word Cross & R-- & Flag Frenzy & R-- \\
\hline ??? Tricky Trivia & R-- & 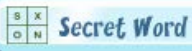 & R-- \\
\hline Jigsaw Jam & $R=$ & 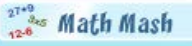 & $R=-$ \\
\hline MENU & & & \\
\hline
\end{tabular}

Figure 2. Moshi Monsters "Hall of Puzzles"

The analysis of puzzles in the "Hall of Puzzles" is presented in Table 2.

Table 2. Category of Hall of Puzzles

\begin{tabular}{l|c|c|l}
\hline \multicolumn{1}{c|}{ Puzzle games } & Numeracy & Logic & \multicolumn{1}{c}{ Explanation of games } \\
\hline Bubble Trouble & & O & $\begin{array}{l}\text { Selecting a color of dots that is not touching another color } \\
\text { of dots }\end{array}$ \\
\hline Color Chaos & & O & $\begin{array}{l}\text { Selecting multiple different colors written in different } \\
\text { colors }\end{array}$ \\
\hline Eyes Spy & $\mathrm{O}$ & & Counting the multiple eyes as shown \\
\hline Word Cross & & $\mathrm{O}$ & Selecting two words overlapping each other \\
\hline Tricky Trivia & & $\mathrm{O}$ & Selecting an answer to a common sense question \\
\hline Jigsaw Jam & & $\mathrm{O}$ & Selecting a puzzle piece which fits into the center outline \\
\hline Time Tangle & $\mathrm{O}$ & & Selecting a time on the clock \\
\hline Shape Shake & $\mathrm{O}$ & & Counting the number of shapes of the same color \\
\hline Line Dance & $\mathrm{O}$ & & Counting the number of lines \\
\hline Flag Frenzy & & $\mathrm{O}$ & Selecting the country's flag \\
\hline Secret Word & & $\mathrm{O}$ & Finding the hidden word in the grid \\
\hline Math Mash & $\mathrm{O}$ & & Performing four fundamental arithmetic operations \\
\hline Number Jumble & $\mathrm{O}$ & & Finding the number that is not present \\
\hline Master of Moshi & & $\mathrm{O}$ & Counting the number of shapes \\
\hline Spelling Spree & & $\mathrm{O}$ & Finding the correct spelling of the shown word \\
\hline Moshi Multiply & $\mathrm{O}$ & & Calculating multiplication \\
\hline Alphabet Soup & & $\mathrm{O}$ & Finding the alphabet that does not appear \\
\hline Next Number & $\mathrm{O}$ & & Finding the next number to the one shown \\
\hline Word Wrap & & $\mathrm{O}$ & Finding the word with same meaning \\
\hline Monster Maze & & $\mathrm{O}$ & Finding the path to save the monster \\
\hline
\end{tabular}




\subsection{Debriefing Questions}

The debriefing was scaffolded with open-ended questions based on the EIAG model of experiential learning. Debriefing questions include four stages: experience (e.g., “What were you trying to do?”), identify (e.g., “How did you feel when...?”, "What did you say when..?”), analyze (e.g., "What problems did you face and how did you attack them?”, "What relationships do you see between...?”) and generalize (e.g., "What parallels do you see between the elements of the game and the real world?”). All participants were scaffolded with the same debriefing questions. While the self-debriefing group wrote their reflections individually, the team-debriefing group first discussed the questions collaboratively and then wrote their reflections by themselves.

\subsection{Experiment}

Motivation and self-efficacy scales were administered as pre-tests before the experimental process in order to see if the students' entry levels were the same in terms of self-efficacy and motivation scores. The purpose of the pre-test was to determine a student's baseline knowledge or preparedness for an educational experience or course of study. After the pre-tests, the teacher explained how to play the game and the how to do the debriefing. The participants then played Moshi Monsters until they all reached the third level. This was done to ensure that players have the same gaming ability in order to minimize the intervening effects on the dependent variables due to their lack of in gaming ability. This pre-play to start with the same gaming level took about 35 to 40 minutes. Tutoring on how to play the game took about 15 minutes and the rest of 20 - 25 minutes were taken to reach the third level of the game. None of the students knew of the Moshi Monsters game before the experiment. Game activities were performed at their own schools and each student was assigned to one computer in the computer laboratory.

For this study, they played the game until they all reached the third level of competence and playing ability. After that, they were then randomly assigned into one of two debriefing groups: self-debriefing and team debriefing. Each participant in the two groups performed one of the debriefings conditions: in-game debriefing and post-game debriefing (see Fig. 3).

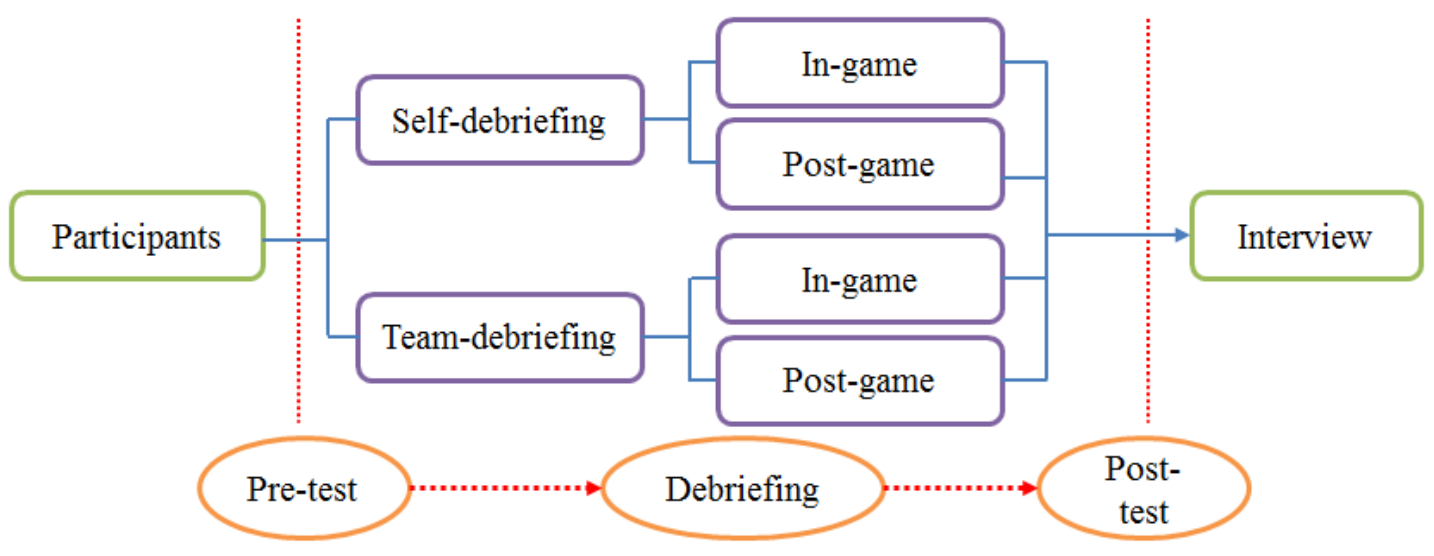

Fig 3. Procedure of the experiment

For a period of two months during the experiment, each group of students played the game during a given time in the computer room and performed assigned debriefing activities, if any. Students in the self-debriefing as well as in the team-debriefing group played the game three days a week over nine weeks. Thus, the experiment lasted for 27 days.

Each day during the experiment is equal to one session which comprised of 60 minutes of game playing, 10 minutes of break time, 60 minutes of debriefing, 10 minutes of break time, and 40 minutes of debriefing for the post-game debriefing. For the in-game debriefing, the first and the second 60 minutes of game play were replaced with 40 minutes of game play plus 20 minutes of debriefing activity. The 40 minutes of debriefing at the last for the post-game debriefing was replaced with the 40 minutes of game play plus for the in-game debriefing. 
Thirty participants in the self-debriefing group played the game and performed debriefing in a computer classroom. The thirty two participants in the team-debriefing group did the same activities in a different computer classroom. In both computer rooms, one facilitator was present in order to manage time allocation for the game play and in order to guide debriefing procedures. The facilitator used the same protocol to explain the debriefing procedure in all types of debriefing sessions.

While the participants in the self-debriefing group worked through the debriefing questions by themselves and then wrote their own reflections, the participants in the team-debriefing group discussed the debriefing questions within the assigned group and then wrote the reflections. While the participants in the in-game debriefing group worked through the discussion questions during the game play, students in the post-game debriefing group worked through the questions after the game.

After the nine week experiment, the motivation and the self-efficacy scales were administered again as post-tests. Semi-structured interviews were conducted with four students from each debriefing group to obtain participants' thoughts on debriefing sessions, their comments on the effect of the process and their suggestions. Interviews were recorded and transcribed verbatim. Repeated and irrelevant statements were removed. Common and prominent statements were presented question by question in the results section.

\section{Results}

\subsection{Quantitative Results}

Before the two-month experimental implementation process, pretests were conducted to test each debriefing group's self-efficacy and motivation levels for the game. As shown in Table 3, there was no significant difference between the pretest scores of the different debriefing groups in terms of self-efficacy $(t=.357, p>.05 ; t=.836, p>.05)$. This result shows that the self-debriefing group and the team debriefing group were homogeneous in terms of their self-efficacy score. This result is the same in both the in-game debriefing group and the post-game debriefing group.

Table 3. Pre-test results for the self-efficacy score

\begin{tabular}{rcccccc}
\hline & Group & $\mathrm{N}$ & $\mathrm{M}$ & $\mathrm{SD}$ & $t$ & $p$ \\
\hline & in-game & 31 & 2.83 & .63 & & \\
Pre- & post-game & 31 & 2.89 & .72 & .357 & .722 \\
\cline { 2 - 7 } test & self-D & 30 & 2.93 & .68 & & \\
& team-D & 32 & 2.79 & .67 & .836 & .407 \\
& & & & & \\
\hline
\end{tabular}

According to the pre-test results of motivation, no significant difference was found between the pretest scores of the different debriefing groups ( $t=1.314, p>.05 ; t=.656, p>.05)$. This result shows that the self-debriefing group and the team debriefing group were homogeneous in terms of their motivation score. This result is the same in both the ingame debriefing group and the post-game debriefing group (Table 4). 
Table 4. Pre-test results for the motivation score

\begin{tabular}{ccccccc}
\hline & Group & $\mathrm{N}$ & $\mathrm{M}$ & $\mathrm{SD}$ & $t$ & $p$ \\
\hline \hline \multirow{2}{*}{$\begin{array}{c}\text { Pre- } \\
\text { test }\end{array}$} & in-game & 31 & 2.72 & .54 & & \\
\cline { 2 - 7 } & post-game & 31 & 2.86 & .31 & & .194 \\
& self-D & 30 & 2.76 & .45 & & \\
& team-D & 32 & 2.83 & .44 & .656 & .514 \\
\hline
\end{tabular}

A two-way ANOVA was conducted to explore the impact of grouping and timing factors on self-efficacy scores. Descriptive analysis indicated that the mean score for the in-game debriefing group $(M=4.98, S D=.75)$ was significantly higher than post-game debriefing group ( $M=4.51, S D=1.09)$ (Table 5).

Table 5. Descriptive statistics for the self-efficacy score

\begin{tabular}{c|c|c|c|c|c|c}
\hline \multirow{2}{*}{$\begin{array}{c}\text { Debriefing } \\
\text { timing }\end{array}$} & \multicolumn{2}{|c|}{ self-D } & \multicolumn{2}{c|}{ team-D } & \multicolumn{2}{c}{ Total } \\
\cline { 2 - 7 } & $M$ & $S D$ & $M$ & $S D$ & $M$ & $S D$ \\
\hline in-game & 4.65 & .57 & 5.30 & .78 & 4.98 & .75 \\
\hline post-game & 4.08 & .95 & 4.90 & 1.08 & 4.51 & 1.09 \\
\hline Total & 4.36 & .82 & 5.10 & .95 & 4.75 & .96 \\
\hline
\end{tabular}

As shown in Table 6, the interaction effect of timing and grouping was not statistically significant, $F(1,58)=.15$, $p=.69$. There was a significant main effect of time, $F(1,58)=4.70, p=.03$ and the effect size was medium (partial $\eta^{2}=.07$ ). There was a significant main effect of grouping, $F(1,58)=11.16, p=.00$ and the effect size was large (partial $\left.\eta^{2}=.16\right)$ (Table 6).

Table 6. Two-way ANOVA results for the self-efficacy score

\begin{tabular}{ccccccc}
\hline Source & SS & $d f$ & $M S$ & $F$ & $p$ & $\eta^{2}$ \\
\hline Model & 12.123 & 3 & 4.041 & 5.323 & .003 & .216 \\
Intercept & 1387.569 & 1 & 1387.569 & 1827.793 & .000 & .969 \\
Timing & 3.571 & 1 & 3.571 & 4.703 & .034 & .075 \\
Group & 8.474 & 1 & 8.474 & 11.163 & .001 & .161 \\
Timing*Group & .116 & 1 & .116 & .152 & .698 & .003 \\
Error & 44.031 & 58 & .759 & & & \\
Total & 1452.180 & 62 & & & & \\
Corrected Total & 56.154 & 61 & & & & \\
\hline
\end{tabular}

Descriptive analysis indicated that the mean score for the team debriefing group ( $M=5.10, S D=.95)$ was significantly higher than the self-debriefing group ( $M=4.36, S D=.82)$ (see Fig. 4). 
Table 7. Pairwise comparison of the self-efficacy post-test score

\begin{tabular}{|c|c|c|}
\hline Source & Mean difference & $p$ \\
\hline post-game self-debriefing vs. in-ga & & \\
\hline self-debriefing & .5667 & .293 \\
\hline vs. in-game team-debriefing & $1.2200 * * *$ & .001 \\
\hline vs. post-game team-debriefing & $.8262 *$ & .050 \\
\hline
\end{tabular}

$* p<.05, * * * p<.001$

As shown in Table 7, there was a significant difference between the mean score of the post-game self-debriefing and that of the in-game team-debriefing $(p<.001)$. In addition, there was a significant difference between the mean score of the post-game self-debriefing and that of the post-game team-debriefing $(p<.05)$. However, the difference between the mean score of the post-game self-debriefing and that of the in-game self-debriefing was not statistically significant.

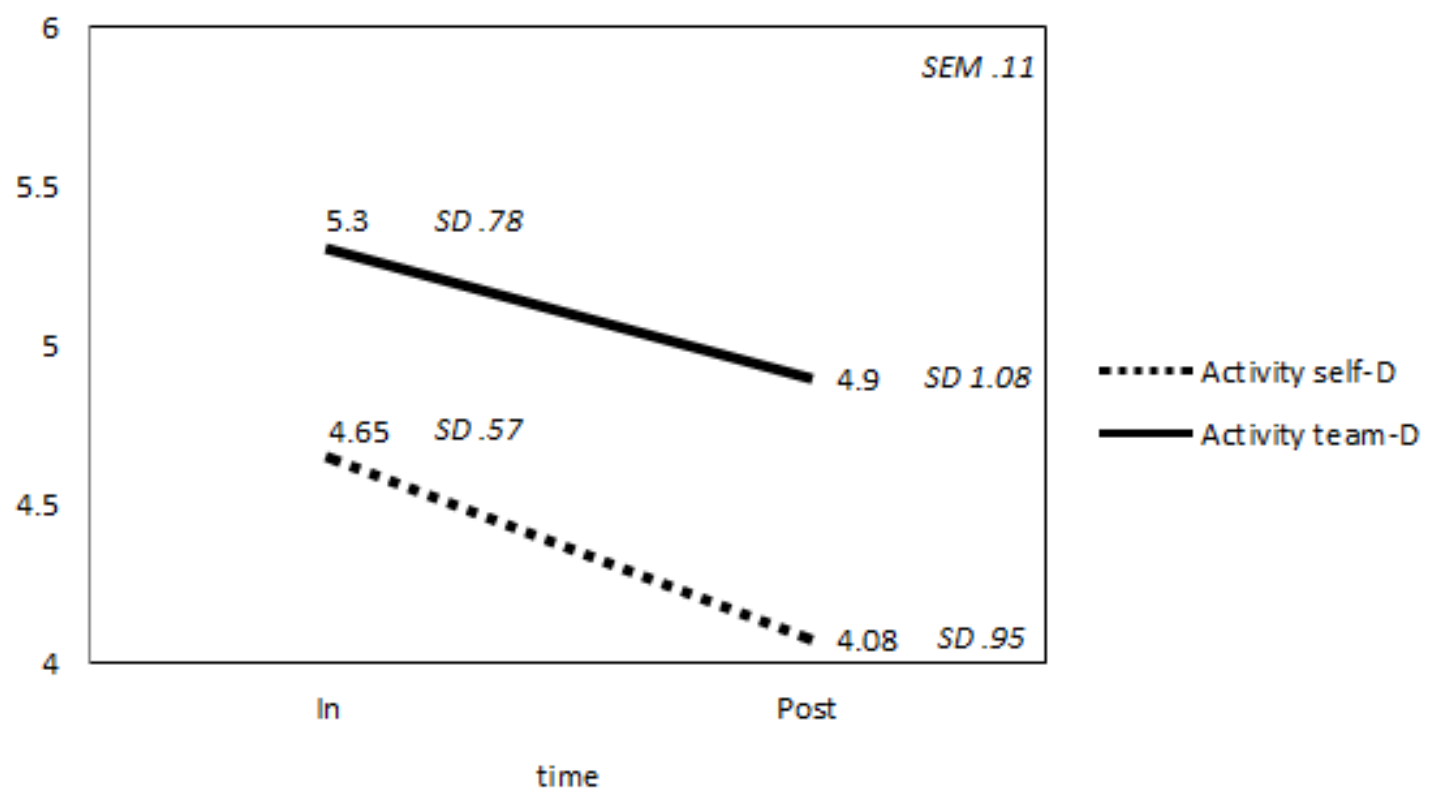

Fig 4. Comparison of means of the self-efficacy score according to grouping and timing factors

A two-way ANOVA was conducted to explore the impact of grouping and timing on motivation scores (Table 9). The interaction effect of timing and grouping was not statistically significant, $F(1,58)=2.19, p=.14$. There was a significant main effect of time, $F(1,58)=19.62, p=.00$, the effect size was large (partial $\eta^{2}=.25$ ). Descriptive analysis indicated that the mean score for the in-game debriefing group $(M=4.80, S D=.65)$ was significantly higher than the post-game debriefing group $(M=4.78, S D=.74)$ (Table 8$)$. 
Table 8. Descriptive statistics for the motivation score

\begin{tabular}{c|c|c|c|c|c|c}
\hline \multirow{2}{*}{$\begin{array}{c}\text { Debriefing } \\
\text { timing }\end{array}$} & \multicolumn{2}{|c|}{ self-D } & \multicolumn{2}{c|}{ team-D } & \multicolumn{2}{c}{ Total } \\
\cline { 3 - 8 } & $M$ & $S D$ & $M$ & $S D$ & $M$ & $S D$ \\
\hline in-game & 4.33 & .60 & 5.24 & .30 & 4.80 & .65 \\
\hline post-game & 3.88 & .63 & 4.33 & .78 & 4.78 & .74 \\
\hline Total & 4.11 & .64 & 4.78 & .74 & 4.46 & .77 \\
\hline
\end{tabular}

There was also a significant main effect of grouping, $F(1,58)=19.51, p=.00$ and the effect size was large (partial $\eta^{2}=.25$ ) Table 9).

Table 9. Two-way ANOVA results for the motivation score

\begin{tabular}{ccccccc}
\hline Source & SS & $d f$ & $M S$ & $F$ & $p$ & $\eta^{2}$ \\
\hline Model & 15.172 & 3 & 5.057 & 13.943 & .000 & .419 \\
Intercept & 1224.246 & 1 & 1224.246 & 3375.335 & .000 & .983 \\
Timing & 7.138 & 1 & 7.138 & 19.618 & .000 & .253 \\
Group & 7.077 & 1 & 7.077 & 19.512 & .000 & .252 \\
Timing*Group & .794 & 1 & .794 & 2.190 & .144 & .036 \\
Error & 21.037 & 58 & .363 & & & \\
Total & 1267.749 & 62 & & & & \\
Corrected Total & 36.209 & 61 & & & & \\
\hline
\end{tabular}

Descriptive analysis indicated that the mean score for the team debriefing group ( $M=4.78, S D=.74)$ was significantly higher than the self-debriefing group ( $M=4.11, S D=.64)$ (see Fig. 5).

Table 10. Pairwise comparison of the motivation post-test score

\begin{tabular}{|c|c|c|}
\hline Source & Mean difference & $p$ \\
\hline $\begin{array}{l}\text { in-game team-debriefing vs. in-game } \\
\text { debriefing }\end{array}$ & $.9026 * * *$ & .001 \\
\hline vs. post-game self-debriefing & $1.3551 * * *$ & .000 \\
\hline vs. post-game team-debriefing & $.4496 * * *$ & .000 \\
\hline
\end{tabular}

$* * * p<.001$

As shown in Table 10, there was a significant difference between the mean score of the in-game team-debriefing and that of the in-game self-debriefing $(p<.001)$. In addition, there was a significant difference between the mean score of the in-game team-debriefing and that of the post-game self-debriefing as well as between that of in-game team debriefing and that of post-game team debriefing $(p<.001)$. 


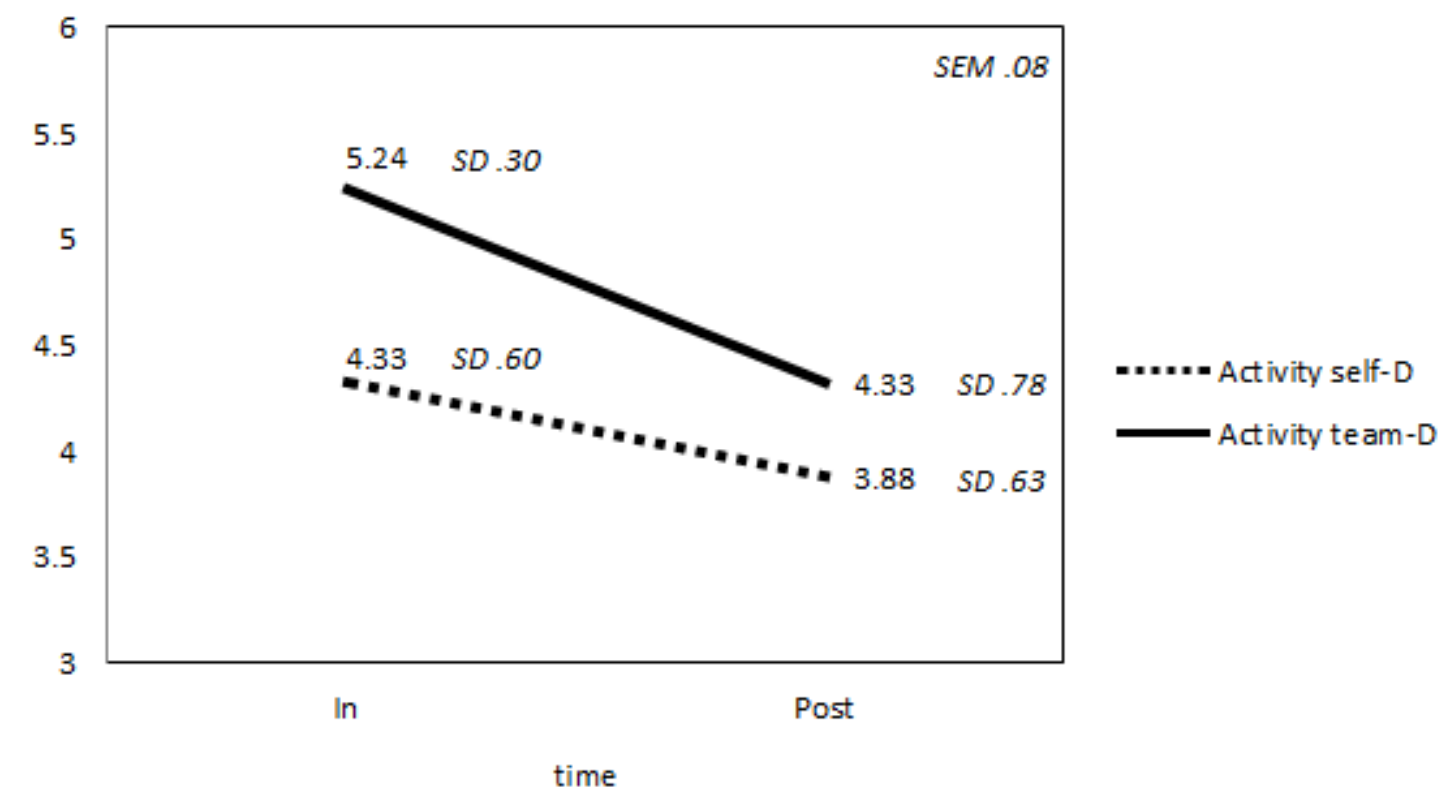

Fig 5. Comparison of means of motivation score according to grouping and timing factors

\subsection{Interview Results}

Semi-structured interviews were conducted with four students from each debriefing group. The answers of eleven students were presented in the next section, because repeating comments and reflections were omitted. For anonymity, students were assigned the codes S1 to S11 and their debriefing groups were stated in parentheses at the end of the statements. Eleven students consisted of 6 males and 5 females. During the semi-structured interviews, the participants were asked various questions about their debriefing experiences. First, the thoughts of the students about positive and negative aspects of the debriefing were requested. Generally the students found debriefing helpful, but they also stated several negative aspects of their debriefing experiences. Some of them explained their reasons with the following statements:

"Debriefing is very helpful. However, I would like to share my experiences with my friends instead of spending my time on debriefing. Debriefing lasted too long” (S1, male)-self, post-game debriefing).

"Debriefing helped me to learn what my friends did during the gaming process, because the game was very helpful to learn social life and it was almost like real life” (S5, male)-team, post-game debriefing).

"It helped me to compare my experiences with my friends. However, it takes too much time and I need to think too much during debriefing” (S6, female)-team, post-game debriefing).

"It is fun to talk about events in the game, but thinking gave me a headache" (S10, female)-team, in-game debriefing).

"It gives me a break and a chance to talk with others about the game, but I did not want to reveal my secret points to others, which is not good” (S9, male)-team, in-game debriefing). 
Second, the opinions of the students on whether debriefing helped them to make connections in their learning were requested. They generally stated positive thoughts, some examples of student statements are:

"It gave me a chance to think about my playing process and it was helpful to solve the problems" (S9, male)-team, in-game debriefing).

"It was helpful for real life. The game and daily life are so similar, thus we became competent to decide where money should be spent and where more money should not be spent” (S2, female)-self, post-game debriefing).

"It encouraged me to compete with my friends" (S5, male)-team, post-game debriefing).

One student stated that debriefing was a burden and preferred to continue playing the game than debriefing:

"Debriefing became a burden to me, however playing the game is more fun” (S11, male)- team, ingame debriefing).

Third, the students were asked about whether their questions or concerns about the game were answered during the debriefing. Students in the team debriefing group generally emphasized collaboration in debriefing sessions, some examples of the statements are:

"Yes, it helped me to understand how to play the game and solve the problems with my friends. I enjoyed teaching the others" (S5, male)-team, post-game debriefing).

"It is very helpful with the assistance of friends" (S10, female)-team, in-game debriefing).

"I think debriefing is a thinking activity which helps a lot to solve the problems about the game" (S3, male)-self, post-game debriefing).

Fourth, students were asked whether debriefing was helpful in clarifying problems during the gaming process. Students generally emphasized the requirement of collaboration during the debriefing process and the socialization effect of team debriefing:

"Yes, but I wish I would have a friend who can tell me how to play the game" (S1, male)-self, postgame debriefing).

"Debriefing was fun because it did not care about my achievement level and it also helped me to maintain friendships” (S5, male)-team, post-game debriefing).

"The hardest thing was to make friends in the game. Debriefing solved this issue” (S7, male)-team, post-game debriefing).

Lastly, student opinions about different modes of debriefing sessions (self vs. team or in-game vs. post-game) were requested. In terms of the grouping factor, students generally preferred the mode that they experienced. Students in the self-debriefing group preferred self-debriefing, students in the Team debriefing group preferred team debriefing. Examples of some student statements are:

“I prefer self-debriefing because it facilitates concentration” (S1, male)-self, post-game debriefing).

"Self-debriefing is better because team debriefing makes it easy to have debates by preventing me to think individually. I think creativity can be maintained through one’s own reflections" (S4, female)-self, post-game debriefing). 
"Team debriefing is better, because it saves time, helps to make friends and it is fun. It can facilitate problem solving much more easily than self-debriefing. It is more efficient because making decisions collaboratively produces better ideas than making decisions individually (S10, female)team, in-game debriefing).

"Team debriefing is better because each member has his/her own strong points and each member can assist the others in solving the problems. Team debriefing can bring out the best from team members in a number of ways, whereas self-debriefing supports developing one solution based on only one person’s idea” (S8, female)- team, post-game debriefing).

On the other hand, one student who was in self-debriefing group preferred the team debriefing group:

"I prefer team debriefing, because more information and ideas can be shared. I would be more interested in debriefing if I were in the team debriefing group, because difficult problems can be easily solved by sharing fresh ideas with the other members" (S9, male)-self, in-game debriefing).

In terms of the timing factor, students had conflicting opinions regardless of which debriefing group they were in. Some of them preferred post-game debriefing by giving "concentration" as a reason; some of them preferred in-game debriefing due to the importance of "immediateness." Examples of student statements are:

"I would prefer debriefing during the game, because it is immediate, so we can apply whatever we thought immediately. This is very effective" (S1, male)-self, post-game debriefing).

"Debriefing during the game is better, because in post debriefing it is hard to remember experiences and it is useless, because it has already finished" (S2, female)-self, post-game debriefing).

"Post debriefing is better because debriefing in the game distracts the players and breaks their concentration. Debriefing during the game has time limit problems” (S6, female)-team, post-game debriefing).

"I would prefer debriefing at the end of the game, because the game should be ended to understand it exactly, thus players can explain the game better” (S11, male)-team, in-game debriefing).

Considering the content of all the comments, it can be said that a high level of satisfaction among the participants regarding the debriefing process in game based learning was recorded. However, several students complained about the length of the debriefing sessions and some of them found the process unnecessary. Students generally emphasized the requirement of collaborative teamwork in debriefing sessions and had conflicting ideas about the timing of the debriefing sessions. Several of them preferred in-game debriefing due to the freshness of the memories and that it was easy to remember the events, while others found that procedure distracting.

\section{DISCUSSION AND CONCLUSION}

In the present study, the effects of different debriefing strategies on motivation and self-efficacy were examined. According to the results, significant main effects of grouping and timing factors on motivation and self-efficacy were found, however the interaction effect of timing and grouping was not significant. The in-game debriefing group outperformed the post-game debriefing group in terms of self-efficacy and motivation levels. According to Van der Meij et al. (2013), the participants' memories are still fresh, thus they can recall actions more easily. This idea was supported by the interview results: "It gives me a break and a chance to talk with others about the game" and "I would prefer debriefing during the game, because it is immediate, so we can apply whatever we thought immediately. This is very effective." In-game debriefing gave students an opportunity to recall the actions more easily and apply whatever they learned in the debriefing sessions immediately. However, it was also seen that this finding of this study was not supported by Van Heukelom et al. (2010) who found that a game experience followed by a debriefing session helped participants better understand the correct and incorrect actions, and was overall more effective compared to debriefing that occurred in game. Some educators believe that uninterrupted debriefing sessions are essential to the game experience (Flanagan et al., 2004). Moreover, according to the interview results several students preferred post- 
game debriefing to in-game debriefing because debriefing during the game distracted them, broke their concentration and had time limit problems. While the main advantage of the in-game debriefing is "immediateness," the main advantage of post debriefing is "concentration."

In the present study, the advantage of "immediateness" dominated the advantage of "concentration." This domination might be due to the type of game. Moshi Monsters is a game that does not require high concentration and does not include time-limited activities, so that debriefing during the game does not break the concentration of the learner. It would be an interesting topic in the future to empirically explore how specific features of games (i.e., the complexity, individual or team play, the environment) affect attitudes toward timing of debriefing. The present study further showed that the team debriefing group outperformed the self-debriefing group in terms of self-efficacy and motivation. According to Li (2010), with the opportunity for collaboration, learners are supposed to have more chance to clarify their concepts and principles and get deeper understanding through mutual discussion. Qualitative results showed that although several students performed debriefing individually, they stated that they would like to share their experiences with their friends instead of spending their time on debriefing. One of them suggested that "difficult problems can be easily solved by sharing fresh ideas with the other members." One of the students summarized the issue with the statement, "Team debriefing is better because each member has his/her own strong points and each member can assist the others in solving the problems. Team debriefing can bring out the best from team members in a number of ways, whereas self-debriefing supports developing one solution based on only one person's idea." However, it was also seen that the finding of this study was not supported by the study of Van der Meij et al. (2013) who found that participants who had engaged in individual debriefings had higher game scores than those who had debriefed collaboratively. To this point, the type of the game is an important factor. If a simulation game aims to support learning by individual participants, self-debriefing may suffice (Peter \& Vissers, 2004). In the study of Van der Meij et al. (2013), the game was "Lemonade Tycoon Deluxe," a strategy game played individually, so that it is expected that self-debriefing may suffice. On the other hand, Moshi Monsters is a social game which includes collaborative activities. When the experience has been undertaken as a team, it is recommended that the debriefing conducted with the team as a whole (Peters \& Vissers, 2004). This result was supported by Tannenbaum and Cerasoli's (2013) approach, in which participant level is one of the important factors that need to be undertaken in the debriefing sessions. Moshi Monsters included collaborative activities that were undertaken as a team.

Semi-structured interviews were conducted to investigate students' views on different debriefing sessions and the quality of the process. Most of the students talked about debriefing sessions positively and stated that the system required them to clarify misunderstandings during the game. However, several students complained about the length of the debriefing sessions, thus they found the sessions too long. Childs and Sepples (2006) found that 10 minutes of debriefing was not sufficient for discussing issues and reflections (as cited in Johnson Pivec, 2011). In the present study, the debriefing sessions took 40 minutes which was sufficient to discuss events, reflections and experiences. The other complaint about the debriefing sessions was the sharing of experiences with team members. Although most of the students preferred sharing their experiences with their friends, some of them did not want to share. Finally, student thoughts were requested on whether debriefing was helpful to clarify problems during the gaming process, students generally found debriefing sessions helpful on that point. Moreover, students generally emphasized the requirement of collaboration during the debriefing process and the socialization effect of team debriefing. These comments support the quantitative results, showing that the debriefing team outperformed the self-debriefing group on game motivation and self-efficacy.

Various debriefing strategies have been used to support learning in educational games or simulations. The present study compared the most common debriefing approaches and investigated the quality of the debriefing sessions. The results showed that debriefing sessions conducted in the middle of the game generated better outcomes than debriefing sessions conducted after the game. Although several students stated that debriefing during the game distracted them and broke their concentration, most of the students emphasized the "immediateness" of the debriefing sessions. Students can benefit more from the in-game debriefing sessions as their memories are fresh and they can apply what they have learned immediately. It is an interesting result that most of the students emphasized the requirement of collaboration in debriefing sessions whether they were in the team debriefing group or not. Although Van der Meij et al. (2011) and Van der Meij et al. (2013) could not find any advantages of team debriefing, the discrepancy can be due to the game type (social game vs. individual game). Although the results showed the superiority of team debriefing, several learners preferred individual debriefing. Some of the learners do not prefer sharing their experiences with team members. In future studies, learners can be categorized according to their characteristics such 
as learning strategies, demographic features, personal characteristics, goal orientations, socio-cultural differences and pre-knowledge, thus learner characteristics can have an effect on the learners' preferences and the learning outcomes, respectively.

Clarifying misunderstandings and giving students the opportunity to revise the events made them feel more confident in their ability to reach the specific goals in the game. Their confidence can be maintained by increasing beliefs in their capabilities. Motivation and self-efficacy are the important factors that have a significant effect on performance and learning in game based learning environments (Wouters et al., 2013). According to the meta- analysis of Wouters et al. (2013), learners in educational games learned more, relative to those taught with traditional instructional methods, when the game was supplemented with other instructional methods and when multiple training sessions were involved. Debriefing sessions in educational games play an important role in increasing players' motivation and selfefficacy beliefs about the game. The results showed that students' beliefs are different in various debriefing strategies.

In the future, more research could be conducted comparing more than one debriefing strategy with different age groups. Comparative studies are rare and the subjects are generally university students. Educational games and simulations are becoming more popular every day in primary and secondary schools, thus it is recommended that debriefing sessions be integrated in a game based learning environment. It would be interesting to explore how specific features of games (i.e., the complexity of the game, individual or team playing game, the game environment, etc.) and learners' characteristics (i.e., learning strategy, demographic features, personal characteristics, socio-cultural difference and pre-knowledge) affect the outcomes of game play. Moreover, although the main objective of this study was to explore self-efficacy and motivation to play, the effect of debriefing on learning outcomes can also be studied in the future and the relationship between motivation to play and motivation to study can be explored. Learners' motivation and self-efficacy beliefs during educational game play might be important factors for learning, so in the future, relationships between knowledge testing and motivation/self-efficacy testing can be investigated in different debriefing modes.

One of the limitations of the study is that increasing the number of factors reduces the sample size per cell to a small number and raises potential power issues. The study can be replicated with more students and with different age groups. The other limitation of this research is the possible defensiveness of the participants. Normally, individuals could try to defend themselves in self-reported questionnaires. Students wanted to appear more socially acceptable even though they did not write their names on the questionnaires. Thus, defensiveness is a possibility with all research that includes the use of self-reporting that participants may attempt to appear socially acceptable. As a result, participants may have acknowledged fewer problems or negative attributes than really existed. Moreover, motivation and self-efficacy can be measured repeatedly during the experiment. Measuring motivation at different times during the game play can give more elaborative and correct results and show more accurate results of different debriefing modes.

\section{References}

Agarwal, R., Sambamurthy,V., \& Stair, R. M.(2000). Research report: the evolving relationship between general and specific computer self-efficacy an empirical assessment. Information Systems Research, 11(4), 418430.

Asakawa, T. \& Gilbert, N. (2003). Synthesizing Experiences: Lessons To Be Learned from Internet-Mediated Simulation Games. Simulation \& Gaming, 34(1), 10-22.

Astin, A. W. (1999). Student involvement: A developmental theory for higher education. Journal of College Student Development, 40, 518-529.

Bandura, A. (2000). Exercise of human agency through collective efficacy. Current Directions in Psychological Science, 9, 75-78.

Boet, S., Bould, D., Bruppacher, H. R., Desjardins, F., Chandra, D. B., \& Naik, V. N. (2011). Looking in the mirror: self-debriefing versus instructor debriefing for simulated crisis. Critical Care Medicine, 39(6), 1377-1381.

Bond, W., Deitrick, L., Eberhardt, M., Barr, G., Kane, B., Worrilow, C., Arnold, D., \& Croskerry, P. (2006). Cognitive versus technical debriefing after simulation training. Academic Emergency Medicine, 13(3), 276-283.

Bredemeier, M. E., Rotter, N. G., \& Stadsklev, R. (1981). “The Academic Game” as a frame game. Journal of Experiential Learning and Simulation, 3, 73-83. 
This is an author-produced, peer-reviewed version of this article. The final, definitive version of this document can be found online at Journal of Educational Computing Research, published by Sage. Copyright restrictions may apply. doi: 10.1177/0735633115598496

Butler, R. E. (1993). Loft: Full-motion simulation as crew resource management training. Cockpit resource management. San Diego: Academic Press.

Cantrell, M. A. (2008). The importance of debriefing in clinical simulations. Clinical Simulation in Nursing, 4(2), e19-e23.

Childs, J. C. and Sepples, S. (2006). Clinical Teaching by Simulation Lessons Learned from a Complex Patient Care Scenario. Nursing Education Perspectives, 27(3), 154-158. doi: http://dx.doi.org/10.1043/10942831(2006)027[0154:CTBSLL]2.0.CO;2

Chronister, C. \& Brown, D. (2012). Comparison of simulation debriefing methods. Clinical Simulation in Nursing, 8(7), e281-e288. http://dx.doi.org/10.1016/j.ecns.2010.12.005.

Clark, R. E. (1983) 'Reconsidering research on learning from media', Review of Educational Research, 53(4), 445457.

Clark, R. E. (1994). Media will never influence learning. Educational Technology Research and Development, 42(2), 21-29. doi:10.1007/BF02299088.

Creswell, J. W. \& Plano Clark, V. L. (2007). Designing and conducting mixed methods research. Thousand Oaks, CA: Sage Publications.

Dufrene, C. \& Young, A. (2013). Successful debriefing - Best methods to achieve positive learning outcomes: A literature review. Nurse Education Today, 34(3), 372-376. http://dx.doi.org/10.1016/j.nedt.2013.06.026

Fanning, R. M. \& Gaba, D. M. (2007). The role of debriefing in simulation-based learning. Simulation in Healthcare, 2(2), 115-125.

Flanagan, B., Nestel, D., \& Joseph, M. (2004).Making patient safety the focus: crisis resource management in the undergraduate curriculum. Medical Education, 38, 56-66.

Fritzsche, D. J., Leonard, N. H., Boscia, M. W., \& Anderson, P. H. (2004). Simulation Debriefing Procedures. Developments in Business Simulation and Experiential Learning, 31, 337-338.

Gordon, C. \& Buckley, T. (2009). The effect of high-fidelity simulation training on medical surgical graduate nurses' perceived ability to respond to patient clinical emergencies. Journal of Continuing Education in Nursing, 40(11), 491-498.

Grant, J.S., Moss, J., Epps, C., \& Watts, P. (2010). Using video-facilitated feedback to improve student performance following high-fidelity simulation. Clinical Simulation in Nursing, 6(5), e177-e184.

Hall, E. (2011). Mind Candy's Moshi Monsters sets out to be the 'Facebook for kids'. Advertising Age, 82(24), 1-3.

Hawkins, M., McGuire, F.A., \& Backman, K. F. (1999). Preparing Participants for Intergenerational Interaction: Training for Success. NY: Haworth Press.

Johnson Pivec, C. R. (2011). Debriefing after Simu lation: Guidelines for Faculty and Students. Unpublished master's thesis, St. Catherine University, St. Paul, Minnesota.

Kolb, D. A. (1984). Experiential learning: Experience as the source of learning and development. New York: Prentice Hall.

Li, J. (2010). Does Collaborative Self-debriefing Scaffold Digital Game-based Learning Better than Individual Selfdebriefing Does? (Master thesis, Faculty of Behavioural Sciences, University of Twente, Netherlands).

Retrieved from

http://www.ilo.gw.utwente.nl/ilo/index.php?option=com_content\&view=article\&id=26:master-thesis-juolan-li\&catid $=9$ :theses\&Itemid $=4$

McAuley, E., Duncan, T., \& Tammen, V. (1989). Causal attributions and affective reactions to disconfirming outcomes in motor performance. Journal of Sport and Exercise Psychology, 11(2), 187-200.

Morgan, P., Tarshis, J., LeBlanc, V., Cleave-Hogg, D., DeSousa, S., Haley, M., Herold-Mcllroy, J., \& Law, J. (2009). Efficacy of high-fidelity simulation debriefing on the performance of practicing anaesthetists in simulated scenarios. British Journal of Anaesthesia, 103(4), 531-537.

Neill, M. A. \& Wotton, K. (2011). High-fidelity simulation debriefing in nursing education: A literature review. Clinical Simulation in Nursing, 7, e161-e168.

Nicholson, S. (2012). Completing the Experience: Debriefing in Experiential Educational Games. In the Proceedings of The $3^{\text {rd }}$ International Conference on Society and Information Technologies. Winter Garden, Florida: International Institute of Informatics and Systemic, 117-121.

Papastergiou, M. (2009). Digital Game-Based Learning in high school Computer Science education: Impact on educational effectiveness and student motivation. Computers \& Education, 52(1), 1-12.

Pavlas, D. (2010). A Model of Flow and Play in Game-based Learning: The Impact of Game Characteristics, Player Traits, and Player States (Dissertation, University of Central Florida, Florida, USA). Retrieved from http://www.navistudios.net/Pavlas_Davin_A_201012_PhD.pdf 
Peters, V. A. \& Vissers, G. A. (2004). A simple classification model for debriefing simulation games. Simulation \& Gaming, 35, 70-84.

Pfefferbaum, B., Jacobs, A. K., Nitiéma, P., Everly, G. S. Jr. (2015). Child Debriefing: A Review of the Evidence Base. Prehospital and Disaster Medicine, 30(3), 306-315. doi:10.1017/S1049023X15004665.

Quinsland, L. \& Ginkel, A. (1984). How to Process Experience? Journal of Experiential Education, 7(2), 8-13.

Reed, S. J. (2012). Debriefing Experience Scale: Development of a Tool to Evaluate the Student Learning Experience in Debriefing. Clinical Simulation in Nursing, 8, e211-e217.

Savoldelli, G., Naik, V., Park, J., Joo, H., Chow, R., \& Hamstra, S. (2006). Value of debriefing during simulated crisis management: oral versus video-assisted oral feedback. Anesthesiology, 105(2), 279-285.

Schön, D. A. (1983). The reflective practitioner: The Reflective Practitioner: How Professionals Think in Action, Basic Books. USA.

Schunk, D. H. (1991). Self-efficacy and academic motivation. Educational Psychologist, 26, 207-231.

Schwarzer, R., \& Jerusalem, M. (1995). Generalized self-efficacy scale. In J. Weinman, S. Wright, \& M. Johnston (Eds.) Measures in health psychology: A user's portfolio. Causal and control beliefs. (pp. 35\{37). Windsor, UK: NFER-NELSON.

Shinnick, M.A., Woo, M., Horwich, T.B., \& Steadman, R. (2011). Debriefing: the most important component in simulation? Clinical Simulation in Nursing, 7(3), e105-e111.

Sims, R. R. (2002). Debriefing experiential learning exercises in ethics education. Teaching Business Ethics, 6(2), 179-197.

Tannenbaum, S. I. \& Cerasoli, C. P. (2013). Do Team and Individual Debriefs Enhance Performance? A MetaAnalysis. Human Factors: The Journal of the Human Factors and Ergonomics Society, 55(1), 231-245.

Thiagarajan, S. (2004). Six Phases of Debriefing. Play for Performance. Retrieved from http://thiagi.net/archive/www/pfp/IE4H/february2004.html\#Debriefing

Van der Meij, H., Leemkuil, H., \& Li, J-L. (2013). Does individual or collaborative self-debriefing better enhance learning from games? Computers in Human Behavior, 29(6), 2471-2479.

Van der Meij, H., Albers, E., \& Leemkuil, H. (2011). Learning from games: Does collaboration help? British Journal of Educational Technology, 42(4), 655-664.

Van Heukelom, J. N., Begaz, T., \& Treat, R. (2010). Comparison of postsimulation debriefing versus in-simulation debriefing in medical simulation. Simulation in Healthcare, 5(2), 91-97.

Vos, N., Van der Meijden, H., \& Denessen, E. (2011).Effects of constructing versus playing an educational game on student motivation and deep learning strategy use. Computers \& Education, 56(1), 127-137.

Welke, T., LeBlanc, V., Savoldelli, G., Joo, H., Chandra, D., Crabtree, N., \& Naik, V. (2009). Personalized oral debriefing versus standardized multimedia instruction after patient crisis simulation. Anesthesia and Analgesia, 109(1), 183-189.

Wouters, P., van Nimwegen, C., van Oostendorp, H., \& van der Spek, E. D. (2013). A Meta-Analysis of the Cognitive and Motivational Effects of Serious Games. Journal of Educational Psychology, 105(2), 249-265. doi: 10.1037/a003131. 